\title{
Aislamientos endofíticos de Colletotrichum spp. a partir de hojas y ramas de mango (Mangifera indica L.) cultivar Azúcar en el municipio de Ciénaga, Magdalena, Colombia
}

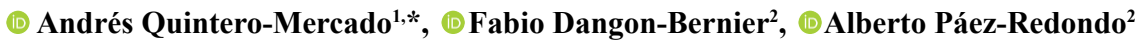 \\ ${ }^{1}$ Facultad de Ciencias Exactas y Naturales, Universidad de Caldas, Manizales, Colombia \\ ${ }^{2}$ Programa de Ingeniería Agronómica, Facultad de Ingeniería, Universidad del Magdalena, Santa Marta, Colombia
}

\begin{abstract}
Resumen
La antracnosis es la enfermedad más limitante en cultivos de mango en el departamento del Magdalena, Colombia, pues causa pérdidas de 40 a $50 \%$ de la cosecha. A nivel mundial, se registran pérdidas en campo hasta de $51 \%$ y en poscosecha, de 20 a $30 \%$. El agente causal, Colletotrichum spp., es un hemibiótrofo que inicialmente no produce síntomas en su hospedante, pero después se torna necrotrófico. El endofitismo es un estilo de vida del hongo cuyo papel en la patogenia es aún incierto. En este contexto, se propuso la caracterización de aislamientos endofíticos de Colletotrichum spp. a partir de hojas y ramas de mango cultivar Azúcar de un cultivo ubicado en Ciénaga. Se determinó la prevalencia de los aislamientos en hojas y ramas de tres estratos del árbol mediante tres protocolos de extracción: 1) en cámara de cloro, 2) con hipoclorito de sodio al $4 \%$, y 3) con hipoclorito de sodio al $2 \%$. Se describió la morfometría (colonia, conidios y apresorios), se hizo la prueba de patogenia en los frutos y la identificación molecular del aislamiento más virulento. Se obtuvieron nueve cepas endofíticas, ocho de hojas y una de ramas. La mejor extracción (18,2 \%) se logró con el hipoclorito de sodio al $2 \%$; la prevalencia fue mayor en el estrato superior (10 \% de las muestras) y en las hojas ( $8,9 \%$ de las muestras). Las cepas endofíticas indujeron lesiones de 0,65 a $19,7 \mathrm{~mm}$ de diámetro y la más virulenta (HP3A-4) se identificó molecularmente como C. tropicale, siendo este el primer registro en Colombia del hongo como endófito patogénico en el mango. Se concluyó que es posible encontrar Colletotrichum como endófito en hojas y ramas de mango y que puede causar infección al inocularse en los frutos, evidenciando así una gran probabilidad de que actúe como un inóculo oculto para el desarrollo de la antracnosis en el mango. (C) 2019. Acad. Colomb. Cienc. Ex. Fis. Nat.
\end{abstract}

Palabras clave: Hemibiotrofo; Prevalencia; Patogenicidad; Inóculo oculto; C. tropicale.

Endophytic isolation of Colletotrichum spp. from the leaves and branches of mango (Mangifera indica 1. ) cultivar Azúcar in the municipality of Ciénaga, Magdalena, Colombia

\begin{abstract}
Anthracnose is the most limiting disease in mango crops in the department of Magdalena (Colombia), causing crop losses between 40 and $50 \%$; worldwide, losses in the field of up to $51 \%$ of the crop have been reported and between 20 and $30 \%$ in postharvest. The causal agent, Colletotrichum spp., has a hemibiotrophic lifestyle, initially does not induce symptoms in its host, but later it changes to a necrotrophic stage. Endophytism is a lifestyle of Colletotrichum, but its role in pathogenicity is still uncertain, which led us to characterize endophytic isolates of Colletotrichum spp. from leaves and branches of mango, cultivar Azúcar, from a crop located in Ciénaga (Magdalena). The prevalence of the isolates in leaves and branches was determined considering three strata of the tree using three extraction protocols: (1) Chlorine chamber; (2) $4 \%$ sodium hypochlorite, and (3) $2 \%$ sodium hypochlorite. Morphometric descriptions included the colony, the conidia, and the appressoria. We tested pathogenicity in fruits and carried out the molecular identification of the most pathogenic isolates. We obtained nine endophytic isolates, eight in leaves and one in branches. The best extraction (18.2\%) protocol was the one using $2 \%$ sodium hypochlorite. The highest prevalence was found in the upper strata of the tree ( $10 \%$ of the samples) and in the leaves ( $8.9 \%$ of the samples). The endophytic strains induced lesions diameter between $0,65-19,7 \mathrm{~mm}$ in diameter in fruits. The most virulent strain (HP3A-4) was identified as C. tropicale by molecular techniques. This is the first report in Colombia of this fungus acting as pathogenic endophyte on mango. The present study indicated that it is possible to find Colletotrichum as an endophyte in mango leaves and branches, which can cause infection when inoculated in fruits and evidences its high hidden inoculum potential for the development of anthracnosis. (C) 2019. Acad. Colomb. Cienc. Ex. Fis. Nat.
\end{abstract}

Keys words: Hemibiotrophic; Prevalence; Pathogenicity; Hidden inoculum; C. tropicale.

*Correspondencia:

Andrés Felipe Quintero Mercado; aquinmer88@gmail.com, Recibido: 4 de noviembre de 2018, Aceptado: 22 de febrero de 2019 ,

Editor: Jairo Castaño Zapata 


\section{Introducción}

La antracnosis, enfermedad causada por especies del hongo Colletotrichum, es la principal limitación de la productividad del mango (Mangifera indica L.) en zonas productoras de esta especie frutícola (Ploetz, 2003). En el departamento de Magdalena las pérdidas en las cosechas oscilan entre 40 y $50 \%$ y, aunque no hay registros que cuantifiquen el daño en la fase de poscosecha, probablemente en esta las pérdidas son mayores (Páez, 1997; Páez, 2003). En otras regiones productoras del mundo se han registrado pérdidas en campo hasta de $60 \%$, y en poscosecha, de 20 a $46 \%$ (Dihn, 2002; Kamle \& Kumar, 2016; Pavitra \& Singh, 2017), a pesar de la implementación de diversas estrategias de manejo en campo y en la poscosecha (Nelson, 2008; Pavitra \& Singh, 2017). A nivel experimental, se han registrado incidencias hasta del $100 \%$ y efectos graves hasta de 21 \% (Hofman, et al., 1997; Chonhenchob, et al., 2011; Chiangsin, et al., 2016).

El manejo de la antracnosis en sistemas productivos de mango tecnificados en el Magdalena se fundamenta en aspersiones calendarizadas de fungicidas para proteger las estructuras reproductivas de los árboles, las cuales se complementan con labores culturales cuando hay daño evidente. En las plantaciones tradicionales prevalecen sistemas de producción extractivos poco tecnificados (Páez, 2003).

Una de las fuentes de inóculo de Colletotrichum spp. corresponde a estructuras del hongo que permanecen quiescentes en la epidermis de los órganos reproductivos y vegetativos del hospedante (Kamle \& Kumar, 2016). Bajo condiciones favorables y factores nutricionales adecuados, los estados quiescentes se activan, especialmente en las etapas de floración o fructificación del cultivo, afectando la inflorescencia y los frutos (Prusky \& Lichter, 2007; Prusky, et al., 2013; Ploetz, 2003; Páez, 2003; Akem, 2006; Osorio, et al., 2009; Dodd, et al., 1991; Sangeetha \& Rawal, 2008; Nelson, 2008), lo que permite que la enfermedad reduzca sustancialmente la productividad en cada árbol y aumente el rechazo de la fruta en los canales de comercialización por la baja calidad del producto (Cartagena \& Vega, 2001; Páez, 2003).

Además de la quiescencia, algunas especies de Colletotrichum pueden permanecer como endófitos en el hospedante, con otro estilo de vida en el cual el microorganismo está activo dentro del tejido vegetal y establece una interacción simbiótica sin causarle daño aparente y sin que haya expresión de síntomas (Hyde \& Soytong, 2008). Este tipo de interacciones se ha considerado como un indicador de evolución concertada y una estrategia de diseminación del microorganismo (Akem, 2006). Sin embargo, recientemente se ha planteado que puede ser un mecanismo del patógeno para evadir respuestas de defensa del hospedante y cambiar a un estado necrotrófico cuando las condiciones ambientales y factores fisiológicos propios del hospedante le son favorables (Arnold, et al., 2007; Hyde \& Soytong, 2008; Vieira, et al., 2014).
A partir del reporte de C. gloeosporioides (Penz.) Penz. \& Sacc. como endófito asintomático (Morales \& Rodríguez, 2006) y los trabajos en Brasil sobre endófitos patogénicos en el mango (Vieira, et al., 2014), se plantea todo un mundo de posibilidades sobre la presencia de especies patogénicas que se comportan como endófitos en algún momento de su ciclo de vida (Delaye, et al., 2013).

Además del conocimiento biológico del endofitismo patogénico de Colletotrichum spp. en el mango, es importante esclarecer cuáles son las especies involucradas, lo cual adquiere mayor importancia cuando, a partir del concepto de concordancia filogenética (Taylor, et al., 2000) surgieron dudas acerca de la especie C. gloeosporioides como patógeno en zonas tropicales (Phoulivong, et al., 2010) y la identificación basada solo en caracteres biológicos (Hyde, et al., 2009). El análisis de ácidos nucléicos proporciona la información más confiable para la clasificación de especies de Colletotrichum, y los estudios biológicos sirven de complemento. La identificación de un grupo de genes distintivos y de regiones de espaciadores internos transcritos (Internal Transcribed Spacers, ITS) han permitido avanzar en el conocimiento de las especies de Colletotrichum asociadas a la antracnosis en diversas especies vegetales, entre ellas el mango y otros frutales (Cai, et al., 2009; Damm, et al., 2010; Cannon, et al., 2012; Afanador, et al., 2014; Ismail, et al., 2015; Gañán, et al., 2015).

El conocimiento de aislamientos endofíticos de Colletotrichum spp. en el mango, sobre todo en las condiciones del trópico, es incipiente o nulo. Por ello, la información exploratoria sobre este aspecto contribuirá a profundizar en el entendimiento de la epidemiología de la enfermedad y abrirá las puertas a nuevos estudios y al establecimiento de modelos de manejo ajustados a esa realidad. Un primer paso es conocer la presencia de estos estados del hongo en los diferentes órganos del árbol y su posible estratificación. En ese contexto, se planteó la comprobación del comportamiento endofítico de especies patogénicas de Colletotrichum aisladas de hojas y ramas de mango cultivar Azúcar provenientes de un cultivo ubicado en Ciénaga, Magdalena, e identificar la especie patogénica mediante el secuenciamiento de genes.

\section{Metodología}

Sitio de estudio y muestreo. Se recolectaron hojas y ramas de los tercios basal, medio y alto de la copa del árbol. Las muestras se tomaron de 10 árboles distribuidos al azar en un cultivo de mango de Azúcar de diez años ubicado en el corregimiento de Cordobita, municipio de Ciénaga, Magdalena (Finca La Ninfa), entre marzo y julio de 2018, el cual registra una precipitación acumulada de $411 \mathrm{~mm}$, una temperatura media de $29{ }^{\circ} \mathrm{C}$ y una humedad relativa promedio de $68 \%$.

El muestreo se hizo cada 15 días durante cinco meses para un total de nueve muestreos. Se tomaron muestras de hojas y ramas asintomáticas, sin ningún tipo de daño 
o alteraciones por agentes bióticos o abióticos. Con la ayuda de tijeras estériles se cortaron los órganos y se depositaron dentro de bolsas plásticas con cierre hermético. Posteriormente, se ubicaron en cajas de icopor limpias para conservarlos hasta su traslado al laboratorio de fitopatología de la Universidad del Magdalena, donde fueron procesadas.

Aislamiento y prevalencia de cepas endófitas. Este primer experimento se hizo en las muestras recolectadas según se describió en la sección anterior.

Extracción de aislamientos endofíticos. Se utilizaron tres protocolos de extracción una vez las muestras se separaron según los factores de evaluación, es decir el órgano muestreado y el estrato del árbol.

Protocolo 1. Exposición en cámara de cloro durante 15 minutos. Esta metodología se basa en lo planteado por Marshall, et al. (1999) sobre el uso de la cámara de cloro para la extracción de endófitos, aplicada aquí con las modificaciones introducidas por Páez (2018). Los órganos (hojas y ramas) se lavaron con agua del grifo para eliminar los residuos y se secaron en servilletas durante 45 minutos para luego cortarlos en secciones de $25 \mathrm{~mm}^{2}$. Posteriormente se desinfectaron en una cámara de extracción de gases marca Maser $\AA$. Se tomó papel de filtro de celulosa marca Whatman ${ }^{\circledR}$ (calibre $150 \mathrm{~mm} \varnothing$ ) y se construyeron conos para depositar allí las secciones de hojas y ramas, lo cuales se rotularon. Los conos se cerraron y se sellaron con cauchos previamente desinfestados con alcohol antiséptico al $70 \%$. En un vaso de precipitados de $150 \mathrm{~mL}$ se depositaron $100 \mathrm{~mL}$ de hipoclorito de sodio en una concentración de $6,25 \%$ y luego se lo colocó en un desecador. Los conos de papel de filtro con las muestras se sujetaron dentro del desecador, de tal manera que quedaron por encima de la boca del vaso, pero sin tocarla. Con una pipeta se tomaron $5 \mathrm{~mL}$ de ácido clorhídrico al $37 \% \mathrm{w} / \mathrm{v}$ y se adicionaron lentamente al vaso que contenía el hipoclorito; luego se tapó el desecador, de manera que quedara herméticamente sellado para evitar la fuga de gases. Los órganos se dejaron expuestos durante 15 minutos. Una vez transcurrido el tiempo, el desecador se destapó y se dejó abierto durante 10 minutos para que saliera el exceso de gases.

Las muestras envueltas en papel de filtro se destaparon dentro de la cámara de flujo y posteriormente se sembraron en medio de agar de papa y dextrosa (PDA); se adicionaron a continuación 200 ppm de gentamicina (Genfar®) previamente preparados bajo condiciones de total asepsia. Se colocaron cinco secciones equidistantes de cada órgano (hoja y rama) dentro de una caja de Petri (100 X $15 \mathrm{~mm}$ ) y se hicieron tres réplicas de cada tratamiento. Posteriormente, se incubaron a $25{ }^{\circ} \mathrm{C}$ durante cinco días en un estante metálico previamente desinfestado con hiploclorito de sodio al $5 \%$.

Protocolo 2. Inmersión de secciones de órganos en hipoclorito de sodio al $4 \%$. Se utilizó la metodología definida en evaluaciones previas (Páez, 2018) a partir de lo propuesto por Stone, et al. (2004) y Photita, et al., (2004). Se lavaron los órganos (hojas y ramas) con agua del grifo para eliminar residuos, se secaron en servilletas durante 45 minutos y se cortaron en pedazos de $25 \mathrm{~mm}^{2}$. Posteriormente se lavaron con agua destilada estéril durante cinco minutos para asegurar la ausencia de material inerte o restos biológicos de insectos o ácaros, entre otros. En la cámara de flujo laminar las muestras se sumergieron en una solución de hipoclorito de sodio al $4 \%$ durante dos minutos, luego se lavaron por inmersión en agua destilada estéril durante dos minutos, se pasaron a una solución de alcohol etílico al $70 \%$ durante otros dos minutos, se lavaron nuevamente con agua destilada estéril por inmersión durante dos minutos y se dejaron secar en servilletas estériles durante 10 minutos. Los pedazos de ramas y hojas se sembraron en medio PDA más 200 ppm de gentamicina (Genfar $\AA$ ) bajo condiciones de total asepsia. Se colocaron cinco secciones de cada órgano de forma equidistante dentro de la caja de Petri. Se hicieron tres réplicas de cada tratamiento. Las muestras se incubaron a $25{ }^{\circ} \mathrm{C}$ durante cinco días en un estante metálico previamente desinfestado con hiploclorito de sodio al $5 \%$.

Protocolo 3. Inmersión en hipoclorito de sodio al $2 \%$. La preparación de las secciones de los órganos, la siembra en medio de cultivo y la incubación se hicieron como en el protocolo 2, pero en este caso la desinfección se hizo por inmersión en hipoclorito de sodio al $2 \%$ durante un minuto $\mathrm{y}$, posteriormente, se hicieron dos lavados con agua destilada de dos minutos cada uno. No se hizo lavado en etanol.

Prevalencia de aislamientos endófitos. De cada estrato se tomaron tres ramas que incluían los tres crecimientos vegetativos (basal, medio y apical) y se obtuvieron secciones de $25 \mathrm{~mm}^{2}$. Se seleccionaron 15 que fueron sembrados de forma equidistante a $2 \mathrm{~cm}$ del borde en tres cajas de Petri, cinco en cada una, con medio de cultivo PDA más 200 ppm de gentamicina (Genfar $\left.{ }^{\circledR}\right)$. Además, de cada rama se desprendieron todas las hojas y se seleccionaron aquellas que no mostraban daños mecánicos por insectos o síntomas de enfermedades; de cada estrato se escogieron cinco hojas, de las que se obtuvieron secciones de $25 \mathrm{~mm}^{2}$, y se sembraron de forma similar a las ramas. Se cuantificó la prevalencia de aislamientos por caja de Petri mediante la fórmula: prevalencia de aislamientos $=$ (positivos/número total sembrados) x 100 .

Los cultivos se inspeccionaron cada dos días durante 20 días para registrar el número de aislamientos positivos para Colletotrichum. Se consideraron como positivos aquellos aislamientos en los que, mediante observaciones bajo el microscopio compuesto de luz, se confirmaron las características del hongo descritas por Damm, et al. (2012). Se utilizó un diseño anidado o jerárquico, con tres factores: estrato del dosel del árbol (bajo, medio y alto), los órganos muestreados (hojas y ramas), y los tres protocolos implementados para el aislamiento de los hongos endófitos; cada tratamiento se replicó nueve veces (muestreos). Se hizo un análisis de contingencias con proporciones entre los factores con el programa Statgraphics Centurion XVI - versión 16.2.04 (32-bits) 2013. Debido a la no normalidad de los datos se hizo un análisis estadístico no paramétrico (prueba de ji al cuadrado) con un nivel de 97,5\% de confianza. 
Descripción morfológica de los endófitos de Colletotrichum spp. A partir de las siembras de secciones de hojas y ramas se obtuvieron los cultivos madre para caracterizar morfológicamente los aislamientos endofíticos de Colletotrichum spp. Para ello se tomaron cultivos de siete días, se plantaron anillos de nueve $\mathrm{mm}$ de diámetro de la zona de crecimiento activo del hongo en el centro de la caja de Petri con el medio y se incubaron a $25^{\circ} \mathrm{C}$. Los aislamientos se sembraron en medio de PDA más 200 ppm de gentamicina $\left(\right.$ Genfar $\left.{ }^{\circledR}\right)$ utilizando tres cajas por aislamiento.

El seguimiento diario se inició a partir de las 24 horas para medir con una regla el crecimiento radial micelial cada dos días durante 10 días. A los siete días, una vez se evidenció un abundante crecimiento micelial y la formación de masas de conidias, se observaron las cajas con un microscopio Leica ICC50 (Leica Application Suite ${ }^{\circledR}$ LAS EZ, Versión 1.7.0 Build: 35), para verificar la presencia de Colletotrichum spp. mediante la comparación morfológica de las estructuras con base en las descripciones de Damm, et al. (2012) y de Weir, et al. (2012).

La colonia se describió cuando los cultivos alcanzaron los diez días, especificando el color y el aspecto del micelio.

Para determinar las diferencias en las tasas de crecimiento de las cepas de Colletotrichum spp. y el diámetro de las conidias (largo y ancho), se utilizó un diseño completamente al azar con tres repeticiones; se hizo un análisis de varianza de una vía (ANOVA) y las medias se compararon mediante pruebas de rango múltiples de Tukey con un nivel de confianza de $95 \%$ con el programa Statgraphics Centurion XVI - versión 16.2.04 (32-bits) 2013.

Patogenia de los aislamientos. Se seleccionaron frutos en estado fenológico 801 según la escala $\mathrm{BBCH}$ (Hernández, et al., 2011), correspondiente a frutos con madurez fisiológica e inicios del cambio de la coloración de la piel. Los frutos se desinfestaron previamente mediante su inmersión total en agua destilada estéril durante dos minutos, en hipoclorito de sodio al $1 \%$ durante un minuto y de nuevo en agua destilada estéril durante dos minutos para luego ser secados en la cámara de flujo laminar y sometidos a aspersión con etanol al $70 \%$, por último, después de un minuto, se lavaron con agua destilada estéril durante dos minutos. Los frutos se colocaron sobre papel kraft estéril durante 45 minutos para que los frutos quedaran completamente secos.

Preparación del inóculo e inoculación. Veinte días después de la siembra los cultivos puros de los aislamientos utilizados para hacer la descripción morfológica se utilizaron para obtener cultivos puros monospóricos según el procedimiento seguido por Ruiz, et al. (2003). Los aislamientos se multiplicaron en medio de PDA con 200 ppm de gentamicina (Genfar®) para la obtención del inóculo.

En la cámara de flujo laminar marca Streamline ${ }^{\circledR}$, se vertieron $20 \mathrm{ml}$ de agua destilada estéril sobre la superficie de las cajas de Petri que contenían los cultivos de siete días; con la ayuda de una espátula pequeña estéril se raspó la superficie de cada crecimiento para recoger todo el contenido fúngico cuidando de no extraer el medio de cultivo. Posteriormente, se depositó en un vaso de vidrio estéril, se agitó en un mezclador de vórtice durante tres minutos y, por último, se pasó por una gasa estéril y se recogió en un nuevo vaso de vidrio estéril. A la suspensión fúngica se le adicionaron $1,5 \mathrm{~mL}$ de Tween ${ }^{\mathrm{TM}} 20$ al $0,1 \%$, y se dejó en el agitador marca $\operatorname{Hach}{ }^{\circledR}$ a $1.000 \mathrm{rpm}$ mientras se realizaba la inoculación en cada fruto.

En la cámara de flujo laminar se tomaron discos de papel de filtro estériles de $0,5 \mathrm{~cm}$ de diámetro y con la ayuda de pinzas de punta plana se colocaron en cuatro puntos del fruto lo más equidistantes posible y cercanos al punto de inserción del pedúnculo.

El conteo de las conidias se hizo en la cámara de Neubauer, con el fin de asegurar una concentración de $5 \mathrm{x}$ $10^{5}$ conidias $/ \mathrm{mL}$. Con una micropipeta se tomaron $10 \mu \mathrm{L}$ de suspensión y se depositaron sobre cada anillo de papel de filtro y se hizo un segundo pase por cada sitio, dejando en total $20 \mu \mathrm{L}$ de suspensión por punto de inoculación. Se hicieron tres réplicas (frutos inoculados) por tratamiento (cepa aislada) para un total de 27 montajes; se utilizaron frutos inoculados con agua destilada estéril como testigo absoluto. Los frutos inoculados se colocaron en cámaras húmedas consistentes en cajas plásticas con tapas de 19 $\mathrm{cm}$ de largo $\mathrm{x} 8 \mathrm{~cm}$ de ancho $\mathrm{x} 7 \mathrm{~cm}$ de alto, cuyo fondo se recubrió con papel absorbente humedecido. Las cajas plásticas se cerraron herméticamente y se colocaron en el cuarto de crecimiento con fotoperiodos de 12 horas de luz y 12 de oscuridad y temperatura entre los 25 y $\operatorname{los} 28^{\circ} \mathrm{C}$.

Seguimiento y evaluación. Se hicieron observaciones diarias durante 15 días para detectar la presencia de síntomas y signos en cada sitio inoculado y determinar el periodo de incubación (PI) y el de latencia (PL). La incidencia (\%) se calculó con base en el número de puntos de inoculación en los que se apreciaban síntomas comparado con el total de puntos inoculados en los frutos.

Para determinar la patogenia o gravedad, se midió el diámetro de la lesión en cada punto inoculado con un calibrador digital pie de rey Stainless ${ }^{\circledR}$ hasta que las condiciones del experimento lo permitieron (coalescencia de lesiones, sobremaduración del fruto, entre otras). Se hicieron nuevos aislamientos a partir de las lesiones típicas de antracnosis resultantes de las inoculaciones, con el fin de cumplir con los postulados de Koch y confirmar su asociación con el desarrollo de las lesiones.

El experimento se evaluó mediante un diseño completamente aleatorizado con tres repeticiones y las diferencias en la virulencia de las cepas endofíticas de Colletotrichum spp. se determinaron mediante ANOVA de una vía, en tanto que las medias se compararon con el procedimiento de diferencia honestamente significativa (honestly significant difference, HSD) de Tukey y un nivel de confianza del $95 \%$ usando el programa Statgraphics Centurion XVI- versión 16.2.04 (32-bits) 2013. 
Rev. Acad. Colomb. Cienc. Ex. Fis. Nat. 43(166):65-77, enero-marzo de 2019 doi: http://dx.doi.org/10.18257/raccefyn.788

Identificación molecular del aislamiento endótico patogénico de Colletotrichum spp. Obtención de micelio para extracción de $A D N$. A partir de cultivos puros de las cajas de Petri, se sembró el aislamiento patogénico identificado como HP3A-4 en caldo arveja suplementado con sacarosa al $20 \%$ según la metodología propuesta por Goodwin, et al. (1992) para obtener micelios puros.

Estandarización protocolo de extracción de ADN. Los micelios obtenidos a partir del cultivo líquido se secaron y se recogieron en tubos Falcon de $15 \mathrm{~mL}$, se maceraron con nitrógeno líquido y se conservaron en el congelador a $-20{ }^{\circ} \mathrm{C}$. Se tomaron aproximadamente $20 \mathrm{mg}$ de micelio macerado para la extracción de ADN usando el estuche OmniPrep ${ }^{\mathrm{TM}}$ for Fungus.

La calidad de la extracción se verificó corriendo una electroforesis en gel de agarosa al $1 \%$ durante 30 minutos a 90 V y 200 mA. La concentración del ADN se verificó con un espectrofotómetro de microvolúmenes modelo Colibrí. Una vez finalizó la corrida de electroforesis, el gel se visualizó en un transiluminador UV y se tomó la respectiva fotografía.

Estandarización del protocolo de amplificación por $P C R$. Para la identificación molecular de los aislamientos se utilizó la técnica de amplificación por reacción en cadena de la polimerasa (polymerase chain reaction, PCR) de las regiones ITS3, ITS4, GAPHD y TUB2 para su posterior secuenciación. En cada reacción se utilizó una mezcla de tampón $1 \times$, 0,2 $\mathrm{mM}$ en cada $\mathrm{dNTP}, 0,5 \mu \mathrm{M}$ de cada cebador, 1,5 $\mathrm{mM}$ de $\mathrm{MgCl}_{2}, 2,5 \mu \mathrm{L}$ de ADN, 0,2 $\mu \mathrm{L}$ de polimerasa Taq y $15,3 \mu \mathrm{L}$ de agua ultra pura $\mathrm{H}_{2} 0$ para completar un volumen final de $25 \mu \mathrm{L}$. La amplificación incluyó un precalentamiento a $95{ }^{\circ} \mathrm{C}$ durante 3 minutos y un ciclo; la desnaturalización a $95{ }^{\circ} \mathrm{C}$ durante 30 segundos y 35 ciclos; el anillamiento a $55^{\circ} \mathrm{C}$ durante 30 segundos y 35 ciclos; una extensión a $72^{\circ} \mathrm{C}$ durante 1 minuto y 35 ciclos y, por último, la extensión final a $72{ }^{\circ} \mathrm{C}$ durante 7 minutos y un ciclo.

Secuenciación. Los productos de PCR ya limpios se enviaron a la Corporación Colombiana de Investigación Agropecuaria Agrosavia C.I. Tibaitatá en Mosquera (Cundinamarca, Colombia), para su respectiva secuenciación en ambas direcciones con el método de Sanger en un equipo de electroforesis capilar ABI 3500 de Applied Biosystems ${ }^{\circledR}$. Para la identificación de la especie, se utilizaron los datos moleculares de los genes estudiados disponibles en el GenBank ${ }^{\circledR}$ del National Center for Biotechnology Information (NCBI) mediante alineación por medio de la Basic Local Alignment Search Tool (BLAST).

\section{Resultados}

Prevalencia de los aislamientos endófitos de Colletotrichum spp. Se obtuvieron ocho morfotipos de Colletotrichum spp. en hojas y uno en ramas de los diferentes estratos del árbol de mango cultivar Azúcar. Los resultados de la prueba de ji al cuadrado, con un nivel de confianza del $95 \%$, indicaron que el aislamiento endófito de Colletotrichum spp. dependía del órgano muestreado. En las 90 secciones de hojas y ramas sembradas para cada tratamiento, hubo una mayor presencia
Aislamientos endofíticos de Colletotrichum spp. de mango cultivar azúcar

de aislamientos endofíticos en las hojas, con una prevalencia de $17,8 \%$, frente a la de $2,2 \%$ en las ramas (Figura 1 ). El $89 \%$ de los aislamientos provenían de las hojas y $11 \%$ de las ramas.

En cuanto la distribución de los aislamientos endofíticos de Colletotrichum spp. en el dosel de los árboles de mango de Azúcar, según la prueba de ji al cuadrado (nivel de confianza del $95 \%$ ) este factor incidió en la frecuencia de los aislamientos de cepas endofíticas del hongo. En el estrato alto se encontró la mayor prevalencia de aislamientos, con $20,6 \%$ del total muestreado, en tanto que en los estratos medio y bajo la frecuencia de aislamientos fue de 3,3 (Figura 2).

Los resultados de la prueba de ji al cuadrado evidenciaron que los métodos de extracción utilizados también afectaron la frecuencia de los aislamientos endofíticos de

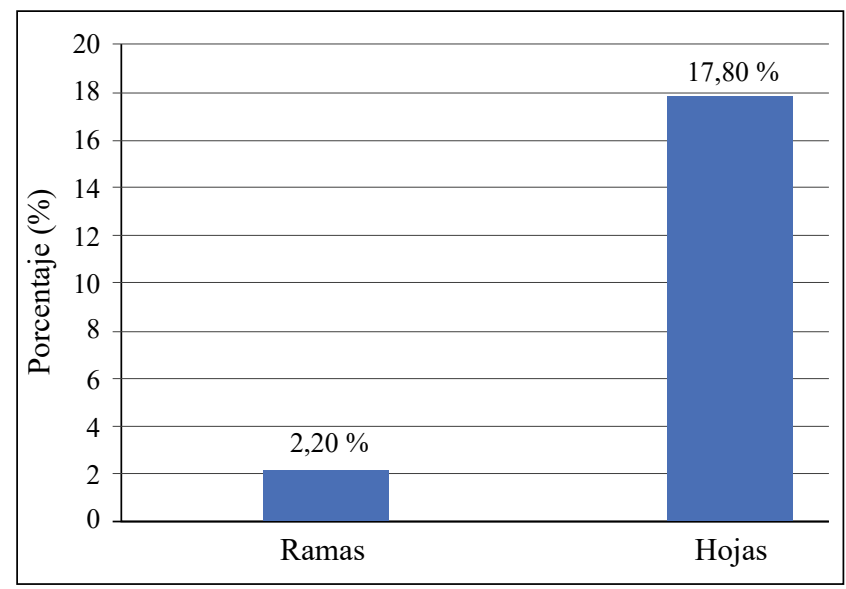

Figura 1. Prevalencia de aislamientos endofíticos de Colletotrichum spp., en los órganos muestreados (hojas y ramas) del árbol de mango cultivar Azúcar, según análisis de contingencia. Prueba de chi-cuadrado (alfa 0,05, Chi-esperado 6,049, Chi-calculado 3,84. Valor p 0,0139).

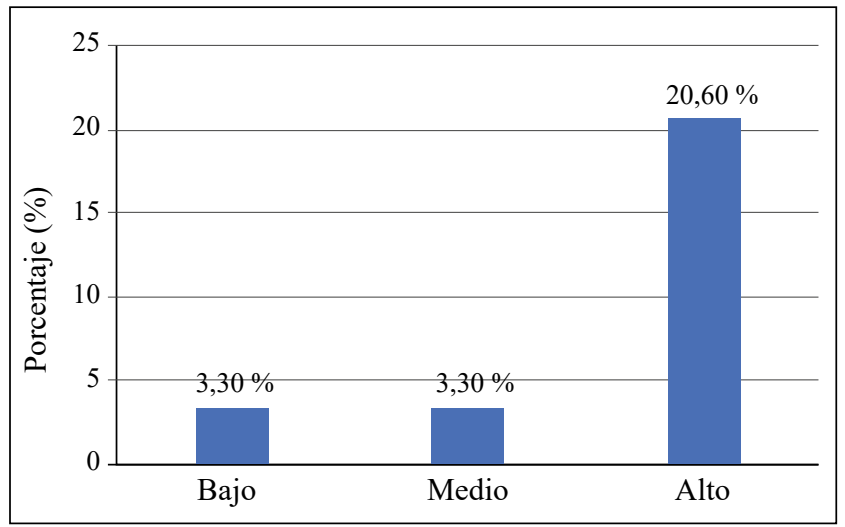

Figura 2. Prevalencia de aislamientos endofíticos de Colletotrichum spp., de acuerdo con el estrato del árbol de mango cultivar Azúcar. según análisis de contingencia. Prueba de chi-cuadrado (alfa 0,05, Chi-esperado 7,4631, Chi-calculado 5,99. Valor p 0,023955). 
Colletotrichum spp. El mayor número se obtuvo con la inmersión en hipoclorito de sodio al $2 \%$, seis cepas, todas provenientes de las hojas, es decir, el 20,7\% del total de las muestras sembradas. Con el protocolo de la cámara de cloro se extrajeron dos cepas endofíticas en hojas y una en ramas, equivalentes al $10 \%$ del total muestreado. Con el protocolo de inmersión en hipoclorito de sodio al $4 \%$ no hubo extracción de endófitos de Colletotrichum spp. (Figura 3).

Descripción morfológica de los aislamientos endófitos de Colletotrichum spp. Aislamiento HP1B-5: colonias en medio de cultivo PDA con una tasa de crecimiento de 8,5 a $9,1 \mathrm{~mm}$ de diámetro día ${ }^{-1}(8,76 \pm 0,3 \mathrm{~b})$ y de textura algodonosa con crecimiento aéreo de color gris claro, zonas de avance de color blanco redondeadas o irregulares, conidióforos hialinos y conidios de 12,47 a 14,46 X 5,1 - 5,72 $\mu \mathrm{m}$ $(13,62 \pm 0,62 \times 5,44 \pm 0,19)$, de forma cilíndrica recta, ápices redondeados y hialinos. No se observaron estructuras de reproducción sexual. El aislamiento procedía de hojas del tercio bajo del árbol y se aisló con el protocolo 1 (cámara de cloro) (Figura 4 A).

Aislamiento HP3A-7: colonias en medio PDA con una tasa de crecimiento de 8,7 a 9,6 mm de diámetro día ${ }^{-1}(9,1$ $\pm 0,45)$, de textura algodonosa con crecimientos sobre el medio de color amarillo naranja y sectores semicirculares e irregulares de color marrón claro y una zona de avance de color blanco, conidióforos hialinos, conidios de 12,3 14,2 X 4,65 - 5,65 $\mu \mathrm{m}(13,13 \pm 0,72$ X 5,22 $\pm 0,38)$ hialinos y cilíndricos redondeados en el ápice y la base, con una cicatriz prominente en el centro, y apresorios de forma variable, simples a ampliamente lobulados e irregulares. No se observaron estructuras de reproducción sexual. El aislamiento procedía de hojas del tercio superior o alto del árbol y se aisló con el protocolo 3 (hipoclorito de sodio al $2 \%$ ) (Figura 4-B).

Aislamiento HP1M-8: colonias en medio PDA con una tasa de crecimiento de 6,2 a 7,1 mm de diámetro día ${ }^{-1}(6,56$ $\pm 0,47)$, de textura algodonosa con crecimiento al ras del medio de cultivo; hacia el centro presentaban un sector circular de color marrón amarillento opaco rodeado por otro sector circular de color naranja con zona de avance de color blanco, así como conidióforos hialinos y conidios de 11,23 - 12,72 X 5,2 - 6,32 $\mu \mathrm{m}(11,97 \pm 0,48$ X 5,67 $\pm 0,36)$, apresorios lobulares irregulares o redondeados, a veces cilíndricos y cortos con lóbulos delgados. No se observaron estructuras de reproducción sexual. El aislamiento procedía de hojas del tercio medio del árbol y se aisló con el protocolo 1 (cámara de cloro) (Figura 4-C).

Aislamiento HP3A-3: colonias en medio PDA con una tasa de crecimiento de 5,5 a 6,1 mm de diámetro día ${ }^{-1}(5,7 \pm$ $0,3)$, de textura algodonosa con crecimiento aéreo de color blanco y de tonalidad rosada a ras del medio, conidios de $10,01-12,56$ X 4,2 - 5,7 $\mu \mathrm{m}(11,03 \pm 0,78 \times 4,9 \pm 0,57)$ hialinos, cilíndricos y rectos, con puntas redondeadas, algunas levemente agudas, apresorios variables en su forma, irregulares y circulares. No se observaron estructuras de

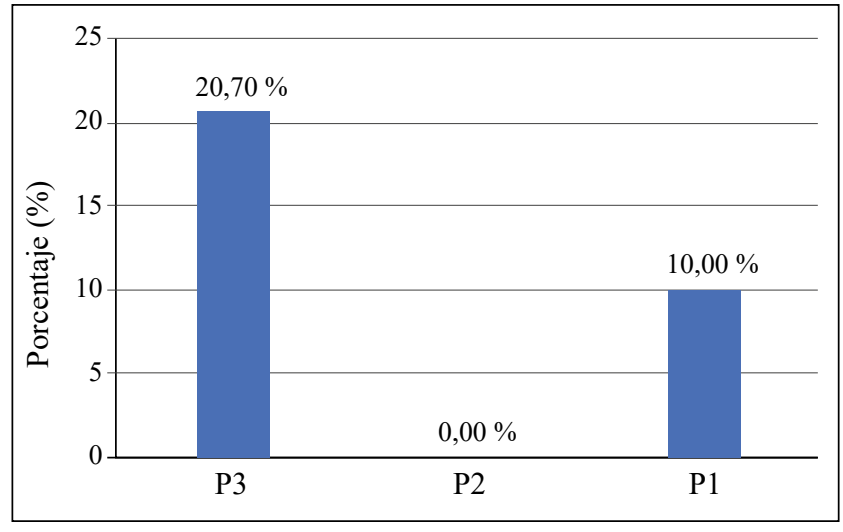

Figura 3. Prevalencia de aislamientos endofíticos de Colletotrichum spp., por protocolo o método de extracción utilizado. P3: Protocolo 3 (Hipoclorito de sodio al 2\%); P2: Protocolo 2 (Hipoclorito de sodio al 4\%); P1: Protocolo 1 (Cámara de Cloro). según análisis de contingencia. Prueba de chi-cuadrado (alfa 0,05, Chi-esperado 7,1264, Chi-calculado 5,99. Valor p 0,02834).

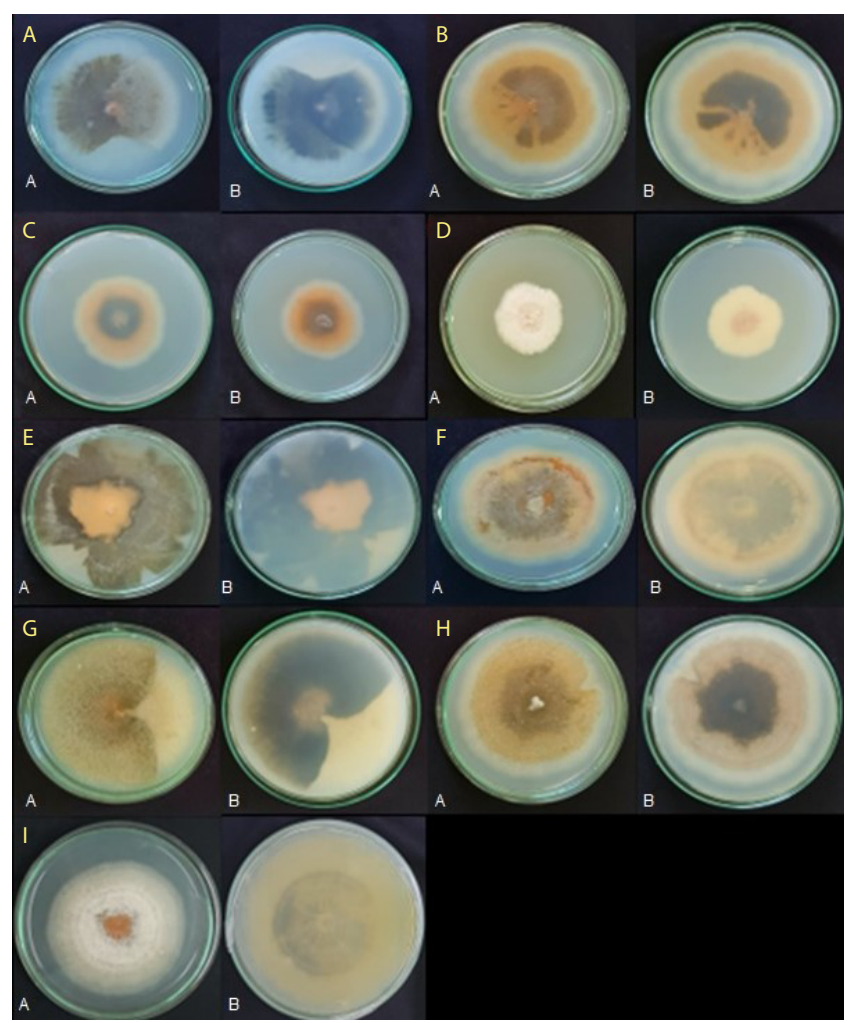

Figura 4. Aislamientos endofíticos de Colletotrichum. A. Anverso de la colonia. B. Reverso de la colonia después de 10 días de crecimiento en PDA a $25^{\circ} \mathrm{C}$. 4-A. Aislamiento HP1B-5. 4-B. Aislamiento HP3A-7. 4-C. Aislamiento HP1M-8. 4-D. Aislamiento HP3A-3. 4-E. Aislamiento HP3A-2. 4-F. Aislamiento HP3A-1. 4-G. Aislamiento HP3A-4. 4-H. Aislamiento HP3A-6. 4-I. Aislamiento RP1A

reproducción sexual. El aislamiento procedía de hojas del tercio superior o alto del árbol y se aisló con el protocolo 3 (hipoclorito de sodio al $2 \%$ ) (Figura 4-D). 
Aislamiento HP3A-2: colonias en medio PDA con una tasa de crecimiento de 9,8 a $10 \mathrm{~mm}$ de diámetro día ${ }^{-1}(9,86$ $\pm 0,11)$, de textura algodonosa y de crecimiento asimétrico a ras del medio en el sector central, rodeado por un crecimiento de color marrón oliva oscuro con micelio aéreo y zona de avance de color gris claro, así como conidios cilíndricos hialinos de 11,64 - 14,4 X 4,4 - 5,9 $\mu \mathrm{m}(12,83$ $\pm 1,02$ X 5,09 $\pm 0,49)$ ligeramente redondeados y con ápice obtuso, acérvulos semicirculares, conidióforos hialinos. No se observaron estructuras de reproducción sexual. El aislamiento procedía de hojas del tercio superior o alto del árbol y se aisló con el protocolo 3 (hipoclorito de sodio al $2 \%$ ) (Figura 4-E).

Aislamiento HP3A-1: colonias en medio PDA con una tasa de crecimiento de 7,5 a $8,3 \mathrm{~mm}$ de diámetro día ${ }^{-1}(7,8$ $\pm 0,40)$, de textura algodonosa con crecimiento marrón grisáceo circunferencial irregular acompañado de micelio aéreo escaso de color gris claro, con crecimiento a ras del medio de color naranja claro con un halo concéntrico naranja más oscuro y zona de avance o crecimiento de color amarillo pálido. Presentaban apresorios circulares y cilíndricos con lóbulos anchos, conidios cilíndricos hialinos de 13,25 - 15,1 $\mathrm{X} 6,78-7,4 \mu \mathrm{m}(13,94 \pm 0,72 \mathrm{X} 7,11 \pm 0,20)$ con puntas redondeadas que disminuían ligeramente hacia el ápice $\mathrm{y}$ acérvulos redondeados. No se observaron estructuras de reproducción sexual. El aislamiento procedía de hojas del tercio superior o alto del árbol y se aisló con el protocolo 3 (hipoclorito de sodio al $2 \%$ ) (Figura 4-F).

Aislamiento HP3A-4: colonias en medio PDA con una tasa de crecimiento de 4,23 a 4,87 $\mathrm{mm}$ de diámetro día ${ }^{-1}$ $(4,43 \pm 0,20)$, de textura algodonosa con sectores distintos, color aceituna grisáceo y amarillo pálido, con sectores de color naranja en el centro y crecimiento de micelio aéreo de color gris (Figura 4 A y B), así como conidios hialinos cilíndricos de 12,3 - 16,65 X 4,23 - 4,87 $\mu \mathrm{m}(13,24 \pm$ $0,64 \mathrm{X} 4,43 \pm 0,20$ ) (Figura $4 \mathrm{C}$ ) y apresorios alargados $\mathrm{y}$ terminales, conidióforos hialinos y acérvulos redondeados. No se observaron estructuras de reproducción sexual. El aislamiento procedía de hojas del tercio superior o alto del árbol y se aisló con el protocolo 3 (hipoclorito de sodio al $2 \%$ ) (Figura 4-G).

Aislamiento HP3A-6: colonias en medio PDA con una tasa de crecimiento de 8,9 a $9,4 \mathrm{~mm}$ de diámetro día ${ }^{-1}(9,1$ $\pm 0,26$ ), de textura algodonosa con crecimiento verde oliva y gris verdoso rodeado de crecimiento color naranja claro y zona de crecimiento o avance de color blanco grisáceo. Presentaban conidios hialinos cilíndricos alargados de 14,89 - 16,65 X 5,9 - 7,1 $\mu \mathrm{m}(15,9 \pm 0,63$ X 6,6 \pm 0,34) y acérvulos circulares. No se observaron estructuras de reproducción sexual. El aislamiento procedía de hojas del tercio superior o alto del árbol y se aisló con el protocolo 3 (hipoclorito de sodio al $2 \%$ ) (Figura 4-H).

Aislamiento RP1A: colonias en medio PDA con una tasa de crecimiento de 8,7 - 9,1 $\mathrm{mm}$ de diámetro dia ${ }^{1}(8,93 \pm 0,20)$, de textura algodonosa con crecimiento aéreo blanco y de color naranja claro a ras del medio con textura acuosa y zona de avance de color blanco grisáceo. Presentaban conidios hialinos cilíndricos alargados de

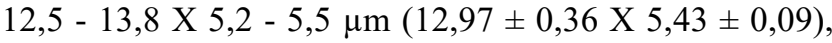
acérvulos circulares, apresorios lobulares irregulares $\mathrm{O}$ redondeados $\mathrm{y}$, a veces, cilíndricos cortos con lóbulos delgados. No se observaron estructuras de reproducción sexual. El aislamiento procedía de ramas del tercio superior o alto del árbol y se aisló con el protocolo 1 (cámara de cloro) (Figura 4-I).

En cuanto al crecimiento micelial y el largo y ancho de las conidias, se presentaron diferencias estadísticas entre los aislamientos $(\mathrm{p}=0,000)$. La cepa HP3A-7 presentó las conidias menos largas y anchas $(11,03 \times 4,9 \mu \mathrm{m})$, en tanto que la cepa HP3A-6 registró las conidias más largas $(15,9$ $\mu \mathrm{m})$, y la cepa HP3A-1 tuvo las conidias más anchas $(7,11$ $\mu \mathrm{m})$. En cuento a la tasa de crecimiento, la cepa HP3A-3 registró el menor valor $\left(5,7 \mathrm{~mm} / \mathrm{día}^{-1}\right)$, y las cepas HP3A-2 y HP3A-4 presentaron las mayores tasas de crecimiento, de $9,86 \mathrm{~mm} /$ día $^{-1}$ en ambos casos (Tabla 1). Las demás cepas registraron valores intermedios, algunos similares y otros no tanto, lo que indica una cierta diversidad morfológica de los aislamientos endofíticos obtenidos.

Patogenia de los aislamientos endófitos de Colletotrichum spp. El período de incubación (PI) de todas las cepas fue de dos días y no se registraron diferencias estadísticas $(\mathrm{p}=0,6347)$ en la prueba HSD de Tukey (nivel de confianza de $95 \%$ ) (Figura 5); los signos se evidenciaron a partir del día 7 en los aislamientos H3PA-4 y HP1B-5. En los demás no fue posible determinar el período de latencia (PL) debido a que los frutos se deterioraron antes de que fueran evidentes los acérvulos y el micelio (Tabla 2).

En cuanto a la incidencia, en las cepas HP1B-5, HP3A4, HP3A-7, HP3A-2 y HP3A-3 fue de $100 \%$, en tantos que el aislamiento HP1M-8 infectó el $75 \%$ de los puntos inoculados y los aislamientos HP3A-1, HP3A-6, RP1A-9 indujeron lesiones en el $50 \%$ de los sitios inoculados en los frutos (Tabla 2).

En cuanto a la gravedad del daño, los aislamientos inoculados presentaron una virulencia variable en los frutos. En la mayoría de los casos se evidenciaron los síntomas característicos de la antracnosis: lesiones de color marrón oscuro a negras, hundidas y prominentes (Figura 6). Hubo diferencias estadísticas en el tamaño de la lesión (diámetro) a los siete días de la inoculación entre las cepas $(\mathrm{p}=0,000)$, lo cual se confirmó con la prueba HSD de Tukey (nivel de confianza de $95 \%$ ). La cepa HP3A-4 causó la lesión de mayor tamaño (19,75 mm), y la cepa HP1M-8 la de menor tamaño (1,6 mm), sin diferencias estadísticas con el control por lo cual se la consideró no virulenta (Figura 7).

Identificación molecular del aislamiento endófito de Colletotrichum spp. de mayor capacidad patogénica. En el aislamiento HP3A-4 se obtuvieron productos de amplificación de la PCR parciales de la región ITS-ADNr (ITS3/ITS4) y de los genes $T U B 2$ y $G A P D H$, con una longitud aproximada de 550, 500 y 250 pares de bases, respectivamente. 
Tabla 1. Resumen de caracteres morfológicos cuantitativos de las cepas endofíticas de Colletotrichum spp., aisladas a partir de hojas y ramas del árbol de mango cultivar Azúcar.

\begin{tabular}{|c|c|c|c|}
\hline \multirow{2}{*}{$\begin{array}{c}\text { Cepas } \\
\text { Colletotrichum spp. }\end{array}$} & \multicolumn{2}{|c|}{ Conidia } & \multirow{2}{*}{$\begin{array}{l}\text { * Tasa de Crecimiento } \\
(\mathrm{mm} / \text { día-1) }\end{array}$} \\
\hline & ${ }^{\Delta} \operatorname{Largo}(\mu \mathrm{m})$ & ${ }^{\Delta}$ Ancho $(\mu \mathrm{m})$ & \\
\hline \multirow[t]{2}{*}{ HP1B-5 } & $13,62 \pm 0,62$ & $5,44 \pm 0,19$ & $8,76 \pm 0,30 \mathrm{bc}$ \\
\hline & $(12,47-14,46)$ & $(5,10-5,72)$ & $(8,50-9,10)$ \\
\hline \multirow[t]{2}{*}{ HP1M-8 } & $11,97 \pm 0,48$ & $5,67 \pm 0,36$ & $6,56 \pm 0,47 d$ \\
\hline & $(11,23-12,72)$ & $(5,20-6,32)$ & $(6,20-7,10)$ \\
\hline \multirow[t]{2}{*}{ HP3A-3 } & $11,03 \pm 0,78$ & $4,90 \pm 0,57$ & $5,70 \pm 0,30 \mathrm{~d}$ \\
\hline & $(10,01-12,56)$ & $(4,20-5,70)$ & $(5,50-6,10)$ \\
\hline \multirow[t]{2}{*}{ HP3A-7 } & $13,13 \pm 0,72$ & $5,22 \pm 0,38$ & $9,10 \pm 0,45 \mathrm{ab}$ \\
\hline & $(12,30-14,20)$ & $(4,65-5,65)$ & $(8,70-9,60)$ \\
\hline \multirow[t]{2}{*}{ HP3A-1 } & $13,94 \pm 0,72$ & $7,11 \pm 0,20$ & $7,80 \pm 0,40 \mathrm{c}$ \\
\hline & $(13,25-15,10)$ & $(6,78-7,40)$ & $(7,50-8,30)$ \\
\hline \multirow[t]{2}{*}{ HP3A-2 } & $12,83 \pm 1,02$ & $5,09 \pm 0,49$ & $9,86 \pm 0,11 \mathrm{a}$ \\
\hline & $(11,64-14,4)$ & $(4,40-5,90)$ & $(9,80-10,0)$ \\
\hline \multirow[t]{2}{*}{ HP3A-4 } & $13,24 \pm 0,64$ & $4,43 \pm 0,20$ & $9,86 \pm 0,15 \mathrm{a}$ \\
\hline & $(12,30-16,65)$ & $(4,23-4,87)$ & $(9,70-10,0)$ \\
\hline \multirow[t]{2}{*}{ HP3A-6 } & $15,90 \pm 0,63$ & $6,60 \pm 0,34$ & $9,10 \pm 0,26 \mathrm{ab}$ \\
\hline & $(14,89-16,65)$ & $(5,90-7,10)$ & $(8,90-9,40)$ \\
\hline \multirow[t]{2}{*}{ RP1A-9 } & $12,97 \pm 0,36$ & $5,43 \pm 0,09$ & $8,93 \pm 0,20 \mathrm{~b}$ \\
\hline & $(12,5-13,80)$ & $(5,20-5,50)$ & $(8,70-9,10)$ \\
\hline
\end{tabular}

* Comparación de medias con un nivel de significancia $\mathrm{P} \leq 0,05$. Prueba de múltiples rangos (HSD) Tukey. $\Delta$ Comparación de medias con un nivel de significancia $\mathrm{P} \leq 0,05$. Prueba de múltiples rangos (LSD) Fisher.

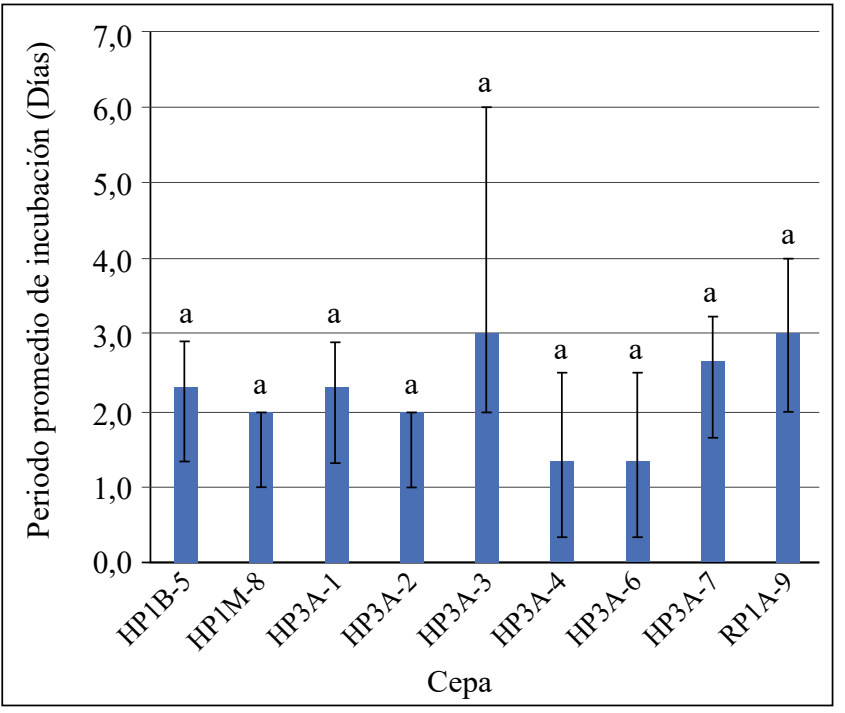

Figura 5. Periodo de incubación (PI) de los aislamientos endofíticos de Colletotrichum spp., en frutos de mango, 10 días después de la inoculación. Las barras de las columnas indican el valor de la desviación estándar de cada una de las medias. Las columnas con letras iguales no difieren significativamente según la prueba de HSD de Tukey $(\mathrm{P} \leq 0,05)$.
Se obtuvieron secuencias parciales de los genes evaluados cuyo número de nucleótidos correspondió a lo observado en los productos de amplificación. Las secuencias se analizaron mediante la herramienta BLAST (Tabla 3).

El aislamiento HP3A-4, el más virulento en frutos de mango cultivar Azúcar, correspondió a la especie $C$. tropicale, taxonómicamente agrupada en el complejo de especies de C. gloeosporioides.

\section{Discusión}

En el estudio se encontró una mayor prevalencia de Colletotrichum spp. endófito en hojas que en ramas. La presencia de organismos endófitos en los árboles de mango puede depender de las características intrínsecas del material vegetal y de su relación con las condiciones del medio en que se encuentran (Petrini, 1991; Vieira, et al., 2014).

Rubini, et al. (2005) aislaron en ramas de cacao comunidades de hongos endófitos en los que se incluyó a $C$. gloeosporiodes. Asimismo, Gamboa \& Bayman (2001) reportaron la presencia de una especie de Colletotrichum a partir de aislamientos de ramas en árboles de G. guidonia (Trompillo, Guaraguao). Sin embargo, en las ramas la abundancia de Colletotrichum como endófito no es muy 
Rev. Acad. Colomb. Cienc. Ex. Fis. Nat. 43(166):65-77, enero-marzo de 2019 doi: http://dx.doi.org/10.18257/raccefyn. 788

Tabla 2. Periodo de Incubación (PI), Periodo de Latencia (PL) e Incidencia (\%), para nueve aislamientos de Colletotrichum inoculados en frutos de mango cultivar Azúcar.

\begin{tabular}{cccc}
\hline No.de CEPA & $\begin{array}{c}\text { Periodo de } \\
\text { incubación } \\
\text { (Días) }\end{array}$ & $\begin{array}{c}\text { Periodo de } \\
\text { latencia } \\
\text { (Días) }\end{array}$ & $\begin{array}{c}\text { Incidencia } \\
\text { (\%) }\end{array}$ \\
\hline HP1B-5 & 2 & 7 & 100 \\
\hline HP3A-4 & 2 & 7 & 100 \\
\hline HP3A-7 & 2 & ND $^{*}$ & 100 \\
\hline HP3A-1 & 2 & ND* & 50 \\
\hline HP3A-6 & 2 & ND* $^{*}$ & 50 \\
\hline RP1A-9 & 2 & ND* $^{*}$ & 50 \\
\hline HP3A-2 & 2 & ND $^{*}$ & 100 \\
\hline HP3A-3 & 3 & ND $^{*}$ & 100 \\
\hline HP1M-8 & 2 & ND $^{*}$ & 75 \\
\hline
\end{tabular}

*ND: No Determinado (las cepas nos mostraron en los frutos inoculados presencia de signos como micelio y acérvulos.

representativa con respecto a otros hongos de las mismas características ecológicas y que aparecen en los mismos órganos (Rubini, et al., 2005; Gamboa \& Bayman, 2001). Los estudios en el mango indican que los aislamientos endófitos de especies de Colletotrichum son más abundantes en hojas que en otros órganos como tallos y flores (Vieira, et al., 2014).

Los métodos de extracción de hongos endofíticos se han basado en los procedimientos convencionales de desinfección, principalmente de las hojas, aunque también se ha recurrido a procedimientos con mayor capacidad desinfectante, como el uso de gases (cámara de cloro), con buenos resultados en cuanto a la diversidad de los hongos aislados (Mariano, et al., 1997; Marshall, et al., 1999; Larran, et al., 2001; Otero, 2002; Schena, et al., 2003; Lu, et al., 2004; Higgins, et al., 2014; Jaber \& Salem, 2014; Murphy, et al., 2014). En nuestro caso, el uso de hipoclorito de sodio al $2 \%$ fue más eficiente que al $4 \%$, así como la cámara de cloro durante 15 minutos, tanto en hojas como en ramas. Es posible que la alta concentración del desinfectante haya afectado las estructuras no infectivas del hongo en los espacios intercelulares e, incluso, en el área intracelular, así como cualquier estructura localizada en la subepidermis, en tanto que con una menor concentración y un menor tiempo de exposición se eliminaron las estructuras fungosas superficiales, pero no se afectaron las estructuras internas del hongo. Se registró una menor eficiencia de la cámara de cloro, lo que podría atribuirse a que el tiempo de exposición a los gases fue letal para los microbios superficiales y endófitos presentes en las microsecciones de hojas y ramas; ello plantea la necesidad de ensayos futuros que permitan ajustar los protocolos para este tipo de órganos.

Según Gamboa (2006), es común encontrar que las comunidades de hongos endófitos varían con los estratos

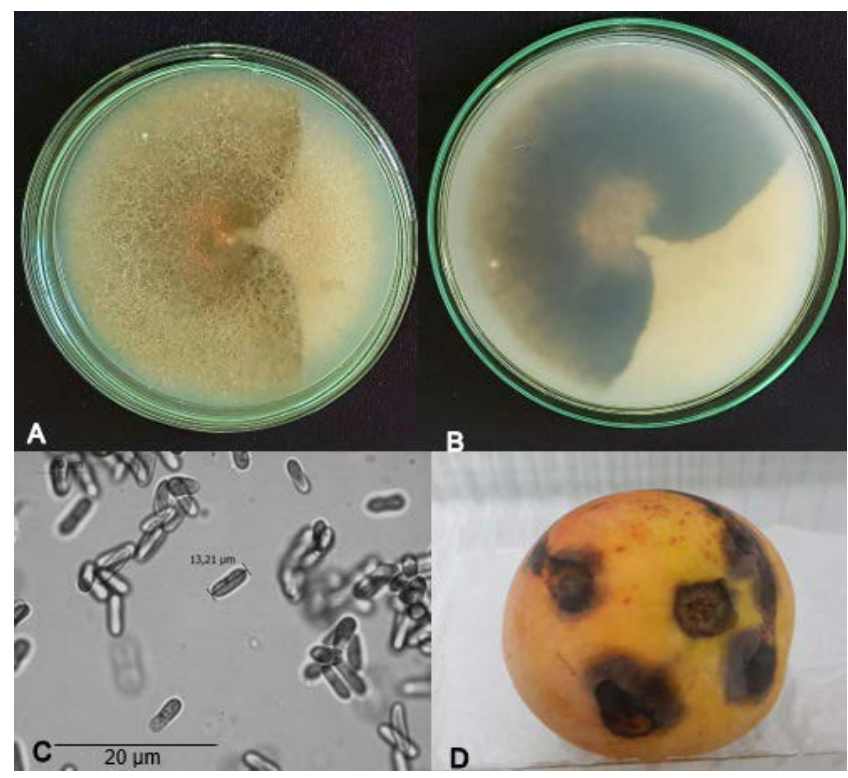

Figura 6. Cepa HP3A-4 (Colletotrichum tropicale): A. Anverso de la colonia. B. Reverso de la colonia después de 10 días de crecimiento en medio PDA. C. Conidios. D. Síntomas en fruto de Mango (Mangifera indica L.) inoculado con Colletotrichum tropicale después de 10 días y a $25^{\circ} \mathrm{C}$; lesiones de color marrón oscuro a negras, hundidas y prominentes.

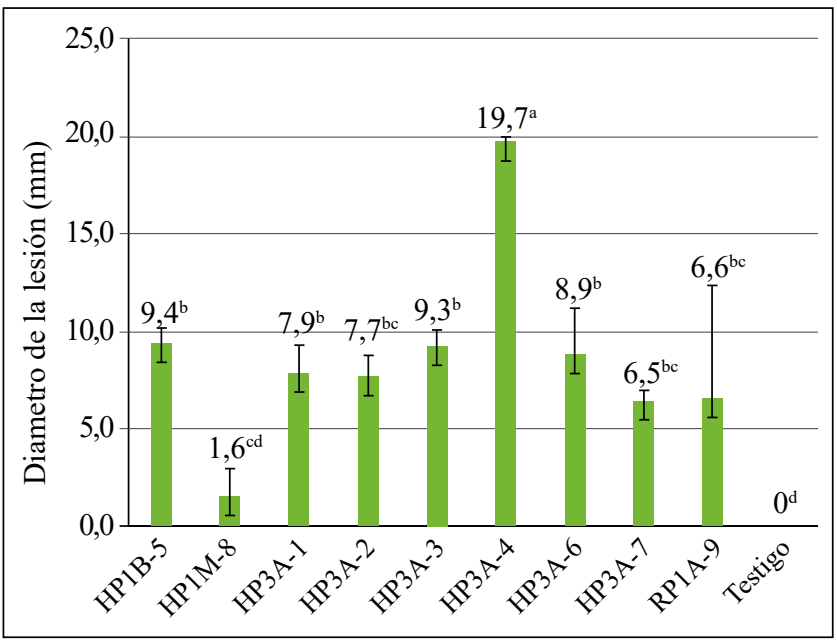

Figura 7. Diámetros de las lesiones causadas por los aislamientos endofíticos de Colletotrichum spp., en frutos de mango, 10 días después de la inoculación. Las barras de las columnas indican el valor de la desviación estándar de cada una de las medias. Las columnas con letras iguales no difieren significativamente según la prueba de HSD de Tukey $(\mathrm{P} \leq 0,05)$.

dentro del dosel, especialmente en la parte más alta donde hay mayor abundancia. Esto puede deberse a que, por su arquitectura compleja, los árboles tropicales generan muchos tipos de microclimas y microhábitats que interfieren en la abundancia de las especies. En el presente estudio se encontró una mayor prevalencia en el estrato superior. 
Tabla 3. Números de acceso en el GenBank ${ }^{\circledR}$ obtenidos para la cepa HP3A-4 de Colletotrichum.

\begin{tabular}{lccc}
\hline Código de la CEPA & & HP3A-4 & \\
\hline Gen & GAPDH & $\beta$ - tubulina 2 & ITS3-ITS4 \\
\hline Porcentaje de homología & $100 \%$ & $99 \%$ & $99 \%$ \\
Especie homologa & C. tropicale & C. tropicale & C. gloeosporioides \\
Accesión en el GENBANK® & KU213601.1 & KU213604 & MH700455.1 \\
\hline
\end{tabular}

Se han detectado aislamientos endofíticos de $C$. gloeosporioides (Penz.) Penz. \& Sacc., C. asianum, C. cliviae, C. dianesei, C. fructicola, C. karstii, C. tropicale, y $C$. endomangiferae con capacidad patogénica en mangos (Morales \& Rodríguez, 2009; Vieira, et al., 2014), especies que, en su mayoría, se han reportado como patógenos causantes de la antracnosis en el mango (Freeman, et al., 1998; Arauz, 2000; Ploetz, 2003; Weirm, et al., 2012; Lima, et al., 2013). En el presente estudio, se confirmó el potencial infectivo de cepas endofíticas de Colletotrichum spp. en mango cultivar Azúcar y que su naturaleza endofítica es un mecanismo que le permite estar oculto en tejidos vegetativos mientras las condiciones no le son favorables para desarrollar la infección, algo ya mencionado en algunos casos específicos (Carroll, 1988; Stone, et al., 2000; Hyde \& Soytong, 2008; De Silva, et al., 2017). La presencia de estas especies patogénicas en hojas y ramas plantea el interrogante sobre su rol en la infección de otros órganos como las flores y los frutos, lo cual llevaría a revisar las estrategias de manejo utilizadas. Prihastuti, et al. (2009) plantearon que los aislamientos endofíticos de Colletotrichum pueden ser patógenos oportunistas, y que es necesario profundizar en el conocimiento de las infecciones naturales provenientes de cepas endofíticas.

La identificación de especies de hongos mediante los métodos convencionales puede resultar equivocada o inexacta (Xiang \& Liang, 2012) debido a su gran diversidad morfológica, y a la variación en su gama de colores, estructuras macroscópicas y microscópicas y a su distribución espacial en el medio de cultivo (Watanabe, 2010; Weir, et al., 2012; Damm, et al., 2012; Freeman, et al., 2001).

En este estudio se evidenció la gran diversidad morfológica de las cepas endofíticas, por lo cual sería arriesgado atribuirla a alguna de las especies descritas actualmente. Los valores del tamaño de las conidias y el crecimiento de la colonia fueron similares a los registrados por Vieira, et al. (2014) en algunas especies de Colletotrichum. Según las variables descritas, los aislamientos HP3A-3, HP3A-6, HP1P-5, HP3A-1, HP3A-7, RP1A-9, HP3A-2 y HP3A-4, se asemejan a las especies de $C$. endomangiferae, C. asianum, C. dianesei, C. fructicola, C. karstii y C. tropicale; sin embargo, dado que dichas características son variables, las especies sugeridas deberán confirmarse mediante la caracterización molecular.

La especie endofítica más patogénica se identificó como C. tropicale, que se encuentra en C. gloeosporioides sensu lato (Vieira, et al., 2014; Weir, et al., 2012). C. tropicale fue reportada por Rojas, et al. (2010) como una especie endófita en hojas de cacao (Theobroma cacao), guanábana (Annona muricata), aguacate (Persea americana), trompillo (Trichilia tuberculata), canfín (Tetragastris panamensis), pentagonia (Pentagonia macrophylla), ucuuba (Virola surinamensis) y laurel blanco (Cordia olliodora) en Panamá, y según Doyle, et al. (2013), se registró en Terpsichore taxifolia en Puerto Rico. En cuanto al mango, se la ha encontrado causando antracnosis en frutos después de inoculaciones controladas y se la aislado como organismo endófito en hojas (Lima, et al., 2013; Vieira, et al., 2014).

En el presente estudio se encontraron aislamientos endófitos de Colletotrichum spp. en hojas y ramas de mango cultivar Azúcar. Tal como se ha registrado en Brasil, la especie C. tropicale, endófito en hojas de mango, causó infecciones en los frutos de esta variedad, confirmándose así su carácter patogénico y altamente virulento. Este registro constituye el primero reportado en mango en Colombia, ya que hasta ahora solo se habían registrado las especies C. gloeosporioides, C. asianum, C. siamense y C. theobromicola (AfanadorKafuri, et al., 2003; Damm, et al., 2012; Gañán, 2014; Pardo, et al., 2016). La existencia de especies endófitas patogénicas indica que hay un gran potencial de inóculo oculto que posiblemente desencadenaría la antracnosis ante cambios fenológicos en el hospedante o el ambiente.

\section{Agradecimientos}

Al fondo Fonciencias, Vicerrectoría de Investigación, Universidad del Magdalena, y a la convocatoria No. 672 "Formación de capital humano de alto nivel para el departamento del Magdalena" de Colciencias, 2014. A la bióloga Eliana Revelo Gómez.

\section{Contribución de los autores}

Andrés Felipe Quintero Mercado: implementación metodológica (aislamiento y purificación del hongo, pruebas de patogenicidad e identificación molecular) análisis de resultados, así como también la revisión bibliográfica y redacción del documento. Fabio Luis Dangon Bernier: toma de muestras, implementación de la metodología en laboratorio (aislamiento y purificación de cepas del hongo, pruebas de patogenicidad), toma de datos, descripción morfológica de los aislamientos, análisis estadístico y redacción del documento. Alberto Rafael Páez Redondo: planificación del 
proceso investigativo, desarrollo de protocolos evaluados, orientación en la implementación del trabajo en laboratorio, análisis bibliográfico, análisis de resultados y redacción y revisión del documento.

\section{Conflicto de intereses}

Los autores declaran no tener ningún conflicto de intereses.

\section{Referencias}

Afanador-Kafuri, L., Minz, D., Maymon, M., Freeman, S. (2003). Characterisation of Colletotrichum isolates from tamarillo, passiflora, and mango in Colombia and identification of a unique species from the genus. Phytopathology. 93: $579-587$.

Afanador-Kafuri, L., González, A., Gañan, L., Mejía, J. F., Cardona, N., Álvarez, E. (2014). Characterization of the Colletotrichum species causing anthracnose in Andean blackberry in Colombia. Plant Disease. 98 (11): 1503-1513.

Arauz, L. (2000). Mango anthracnose: Economic impact and current options for integrated management. Plant Disease. 84: 600-608.

Akem, C.N. (2006). Mango anthracnose disease: Present status and future research priorities. Plant Pathology Journal. 5 (3): 266-273.

Arnold, E., Henk, D., Eells, R., Vilgalys, R. (2007). Diversity and phylogenetic affinities of foliar fungal endophytes in loblolly pine inferred by culturing and environmental PCR. Mycologia, 99(2). 33: 185-206.

Cannon, P. \& Simmons, C. (2002). Diversity and host preference of leaf endophytic fungi in the Iwokrama Forest Reserve, Guyana. Mycologia, 94(2). 33: 210-220.

Cannon, P. F., Damm, U., Johnston, P. R., Weir, B. S. (2012). Colletotrichum-current status and future directions. Studies in mycology. 73: 181-213.

Cai, L., Hide, K. D., Taylor, P. W. J., Weir, B. S., Waller, J., Abang, M. M., Zhang, J. Z., Yang, Y. L., Phoulivong, S., Liu, Z. Y., Prihastuti, H., Shivas, R. G., Mckenzie, E. H. C., Jhonston, P. R. (2009). A polyphasic approach for studying Colletotrichum. Fungal Diversity. 39: 183-204.

Cartagena, J. \& Vega, D. (2001) Fruticultura colombiana. El Mango. Manual de asistencia técnica $\mathrm{N}^{\circ}$ 43. ICA, Sección Nacional de Frutícolas. p.124.

Carrol, G. (1988). Fungal endophytes in stems and leaves: From latent pathogen to mutualistic symbiont. Ecology. 69: 2-9.

Chiangsin, R., Wanichkul, K., Guest, D. I., Sangchote, S. (2016). Reduction of anthracnose on ripened mango fruits by chemicals, fruit bagging, and postharvest treatments. Australasian Plant Pathology. 45 (6): 629-635.

Chonhenchob, V., Kamhangwong, D., Kruenate, J., Khongrat, K., Tangchantra, N., Wichai, U., Singh, S.P. (2011). Preharvest bagging with wavelength-selective materials enhances development and quality of mango (Mangifera indica L.) cv. Nam Dok Mai \#4. J Sci Food Agric. 91: 664-671.

Damm, U., Cannon, P., Woudenberg, J., Crous, P. (2012). The Colletotrichum acutatum species complex. Studies in mycology. 73: 37-113.

Damm, U., Baroncelli, R., Cai, L., Kubo, Y., O'Connell, R., Weir, B., ... Cannon, P. F. (2010). Colletotrichum: Species, ecology and interactions. IMA fungus. 1 (2): 161-165.
De Silva, D., Crous, P., Ades, P., Hyde, K., Taylor, P. (2017). Life styles of Colletotrichum and implications for plants biosecurity. British Mycological Society. 31: 155-168.

Delaye, L., García-Guzmán, G., Heil, M. (2013). Endophytes versus biotrophic and necrotrophic pathogens - are fungal lifestyles evolutionarily stable traits. Fungal Diversity. 60 (1): 125-135.

Dinh, S. Q. (2002). Post-harvest loss of mango due to anthracnose and its infection biology and resistance of mango to the disease. Kasetsart University. p. 2-70.

Dodd, J., Estrada, A., Matcham, J., Jeffries, P. (1991). The effect of climatic factors on Colletotricum gloeosporioides, causal agent of mango anthracnose, in the Philippines. Plant Pathology. 12: 568-575.

Doyle, V.P., Oudemans, P.V., Rehner, S.A., Litt, A. (2013) Habitat and host indicate lineage identity in Colletotrichum gloeosporioides s. 1. from wild and agricultural landscapes in North America. PLoS One 8:e62394

Freeman, S., Katan, T., Shabi, E. (1998). Characterization of Colletotrichum species responsible for anthracnose diseases of various fruits. Plant Disease. 82: 596-605.

Freeman, S., Horowitz, S., Sharon, A. (2001). Pathogenic and Nonpathogenic Lifestyles in Colletotrichum acutatum from Strawberry and Other Plants. Phytopathology. 91: 986-991.

Gañán, L., Álvarez, E., Zapata, J. C. (2015). Identificación genética de aislamientos de Colletotrichum spp. causantes de antracnosis en frutos de aguacate, banano, mango y tomate de árbol. Revista de la Academia Colombiana de Ciencias Exactas, Físicas y Naturales. 39 (152): 339-347.

Gañán, L. (2014). Identificación taxonómica de aislamientos de Colletotrichum spp., asociados con la antracnosis de frutas tropicales en Colombia mediante análisis filogenético multilocus. Tesis, Magister en Fitopatología, Facultad de Ciencias Agropecuarias, Universidad de Caldas. Manizales. Colombia. p. 26-27.

Gamboa, M. \& Bayman, P. (2001). Communities of Endophytic Fungi in Leaves of a Tropical Timber Tree (Guarea Guidonia: Meliaceae). Biotropica. 33 (2): 352-360.

Gamboa, M. (2006). Hongos endófitos tropicales: conocimiento actual y perspectivas. Acta Biológica Colombiana. 11: 3-20.

Hernández, P., Arangurenb, M., Reigc, C., Fernández, D., Mesejoc, C., Martínez, A., Galán, V., Agustí, M. (2011). Phenological growth stages of mango (Mangifera indica L.) according to the BBCH scale. Scientia Horticulturae. 130: 536-540.

Higgins, K., Arnold, A., Coley, P., Kusar, T. (2014). Communities of fungal endophytes in tropical forest grasses: highly diverse host - and hábitat generalists characterized by strong spatial structure. Fungal Ecology. 8: 1-1.

Hyde, K. \& Soytong, K. (2008). The fungal endophyte dilemma. Fungal Diversity. 33: 163-173.

Hofman, P. J., Smith, L. G., Joyce, D. C., Johnson, G. I., Meiburg, G. F. (1997). Bagging of mango (Mangifera indica cv.Keitt') fruit influences fruit quality and mineral composition. Postharvest Biology and Technology. 12 (1): 83-91.

Hyde, K. D., Cai, L., McKenzie, E. H. C., Yang, Y. L., Zhang, J. Z., Prihastuti, H. (2009). Colletotrichum: A catalogue of confusion. Fungal Diversity. 39 (1): 1-17. 
Ismail, A. M., Cirvilleri, G., Yaseen, T., Epifani, F., Perrone, G., Polizzi, G. (2015). Characterisation of Colletotrichum species causing anthracnose disease of mango in Italy. Journal of Plant Pathology. 97 (1): 167-171.

Jaber, R. \& Salem, M. (2014). Endophyte colonization of squash by the fungal entomopathogen Beauveria bassiana (Ascomycota: Hypocreales) for managing zucchini yellow mosaic virus in cucurbits. Biocontrol science and technology. 24: 1096-1109.

Kamle, M., Kumar, P. (2016). Colletotrichum gloeosporioides: Pathogen of Anthracnose Disease in Mango (Mangifera indica L.). In Current Trends in Plant Disease Diagnostics and Management Practices. Springer, Cham. p. 207-219.

Larran, S., Mónaco, C., Alippi, H. (2001). Endophytic fungi in leaves of lycopersicon esculentum Mill. World Journal of Microbiology \& Biotechnology. 17: 181-184.

Lima, N., Batista, M., De Morais Jr, M., Barbosa, M., Michereff, S., Hyde, K., Camara, M. (2013). Five Colletotrichum species are responsible for mango anthracnose in northeastern Brazil. Fungal Diversity. 61: 81-86.

Lu, G., Cannon, P., Reid, A., Simmons, C. (2004). Diversity and molecular relationships of endophytic Colletotrichum isolates from the Iwokrama Forest Reserve, Guyana. Mycological Research. 108 (1): 53-63.

Mariano, R., Fernández De Lira, R., Barbosa Da Silveira, E., Menezes, M. (1997). Levantamento de fungos endofíticos e epifíticos em folhas de coqueiro no nordeste do Brasil. I. Freqüência da populaçao fúngica e efeito da hospedeira. Agrotrópica. 9: 127-134.

Marshall, D., Tunali, B., Nelson, R. (1999). Occurrence of fungal endophytes in species of wild triticum. Crop Science Society of American. 39: 1507-1512.

Morales, V. \& Rodríguez, M. (2009). Microbiota endofítica asociada al cultivo del mango "Haden" (Mangifera indica L.) en el oriente de Venezuela. En Revista UDO Agrícola. 9 (2): 396-398.

Morales, V. \& Rodríguez, M. (2006). Hongos endófitos en plantaciones de mango "Haden" de la planicie de Maracaibo, Venezuela. Instituto Nacional de Investigaciones Agrícolas (INIA), Maracaibo, Venezuela. Rev. Fac. Agron. (LUZ). 23: 273-282.

Murphy, R., Doohan, M., Hodkinson, R. (2015). Persistent fungal root endophytes isolate from a wild barley species suppress seed-borne infections in a barley cultivar. BioControl. 60: 281-292.

Osorio, J., Martínez, E., Hio, J., Aguirre, J. (2009). Estudios de epidemiología y control no convencional de la antracnosis del mango. Informe Técnico Corpoica. Colombia. p 17.

Otero, T., Ackerman, D., Bayman, P. (2002). Diversity and host specificity of endophytic Rhizoctonia - Like fungi from Tropical Orchids. Am J Bot. 89: 1852-1858.

Páez, A. (2018). Diversidad de endófitos en mango cultivar Azúcar. Tesis de doctorado. En proceso.

Páez, A. (2003). Tecnologías sostenibles para el manejo de la antracnosis en papaya y mango. Boletín Técnico $\mathrm{N}^{\circ} 8$. CORPOICA. p. 1-18.

Páez, A. (1997). Respuesta de cultivares de mango (Magnifera indica L.) a la antracnosis en la Costa Atlántica colombiana. Corpoica Ciencia y Tecnología Agropecuaria. 2: 45-53.
Pardo-De la Hoz, C. J., Calderón, C., Rincón, A. M., Cárdenas, M., Danies, G., López-Kleine, L., ..., Jiménez, P. (2016). Species from the Colletotrichum acutatum, Colletotrichum boninense and Colletotrichum gloeosporioides species complexes associated with tree tomato and mango crops in Colombia. Plant Pathology. 65 (2): 227-237. Doi: 10.1111/ ppa. 12410.

Pavitra Kumari, R. \& Singh, R. (2017). Anthracnose of mango incited by Colletotrichum gloeosporioides: A comprehensive review. Int. J. Pure App. Biosci. 5 (1): 48-56.

Petrini, O. (1991). Fungal Endophytes of Tree Leaves. Microbial Ecology of Leaves. Microbial Ecology of Leaves ( $\mathrm{J}$. Andrews \& S. Hirano, eds). p. 179-197.

Ploetz, R. (2003). Diseases of Mango. pp. 327-363. In: R.C. Ploetz (ed.) Diseases of Tropical Fruit Crops. CABI Publishing. Wallingford, UK. p. 544.

Photita, W., Lumyong, S., Lumyong, P., Mckenzie, E.H.C., Hyde, K.D. (2004). Are some endophytes of Musa acuminata latent pathogens? Fungal Diversity. 16: 131-140.

Phoulivong, S., Cai, L., Chen, H., McKenzie, E. H., Abdelsalam, K., Chukeatirote, E., Hyde, K. D. (2010). Colletotrichum gloeosporioides is not a common pathogen on tropical fruits. Fungal Diversity. 44 (1): 33-43.

Prusky, D. \& Lichter, A. (2007). Activation of quiescent infections by postharvest pathogens during transition from the biotrophic to the necrotrophic stage. FEMS Microbiology Letters. 268 (1):1-8. Doi: http://dx.doi.org/10.1111/j.15746968.2006.00603.x

Prihastuti, H., Cai, L., Chen, H., McKenzie, E.H.C., Hyde, K.D. (2009). Characterization of Colletotrichum species associated with coffee berries in northern Thailand. Fungal Diversity. 39: 89-109.

Prusky, D., Alkan, N., Mengiste, T., Fluhr, R. (2013). Quiescent and necrotrophic lifestyle choice during postharvest disease development. Annual Review of Phytopathology. 51: 155-176. Doi: 10.1146/annurev-phyto-082712-102349

Rojas, E., Rehner, S., Samuels, G., Van Bael, S., Herre, E., Cannon, P., Chen, R., Pang, J., Wang, R., Zhang, Y., Peng, Y., Sha, T. (2010). Colletotrichum gloeosporoides s.l. associated with Theobroma cacao and othbbbbber plants in Panamá: Multilocus phylogenenies distinguish host-associated pathogens from asymptomatic endophytes. Mycology. 102 (6):1328-1338.

Rubini, M., Silva-Ribeiro, R., Pomella, A., Maki, C., Welington L. Araújo, W., Deise R. dos Santos, D., Azevedo, J. (2005). Diversity of endophytic fungal community of cacao (Theobroma cacao L.) and biological control of Crinipellis perniciosa, causal agent of Witches' Broom Disease. International Journal of Biological Sciences. 1: 24-33.

Ruiz, C. M., Gutiérrez, L. G., Umaña, G. (2003). Caracterización morfológica y bioquímica de aislamientos de Colletotrichum spp. y su patogenicidad en mango (Mangifera indica L.). Tecnología en Marcha. 16 (1): 55-65.

Sangeetha, C. \& Rawal, R. (2008). Nutritional studies of Colletotrichum gloeosporioides (Penz.) Penz. \& Sacc. The Incitant of Mango Anthracnose. World Journal of Agricultural Sciences. 4 (6): 717-720.

Schena, L., Nigro, F., Pentimone, I., Ligorio, A., Ippolot, A. (2003). Control of postharvest rots of sweet cherries and table grapes with endophytic isolates of Aureobasidium pullulans. Postharvest biology technology. 30: 209-220. 
Scot, N. (2008). Mango anthracnose (Colletotrichum gloeosporoides). University of Hawai. Departament of Plan and Environmental Protection Sciences. p. 1-7.

Stone, J., Bacon, C., White, J. (2000). An overview of endophytic microbes: Endophytism defined. En: Bacon, C \& White, J. Microbial endophytes. New York: Marcel Dekker. p. 3-29.

Taylor, J. W., Jacobson, D. J., Kroken, S., Kasuga, T., Geiser, D. M., Hibbett, D. S., Fisher, M. C. (2000). Phylogenetic species recognition and species concepts in fungi. Fungal genetics and biology. 31 (1): 21-32.

Vieira, W., Michereff, S., De Morais Jr, M., Hyde, K., Câmara, M. (2014). Endophytic species of Colletotrichum associated with mango in northeastern Brasil. En. Fungal Divers. 67: 181-202.
Watanabe, T. (2010). Pictorials atlas of soil and seed fungi: Morphologies of cultured fungi and key to species. $3^{\text {rd }}$ edition. CRC press. p. 3-385.

Wanderley, I., Costa, L., Cavalcanti, M. (2012). Diversity of leaf endophytic fungi in mangrove plants of northeast Brazil. Brazilian Journal of Microbiology. 43 (3): 1165-1173.

Weir, B.S., Johnston, P.R., Damm U. (2012). The Colletotrichum gloeosporioides species complex. Stud Mycol. 73: 115-180.

Xiang, S. \& Liang, D. (2012). Endophytic fungal diversity: Review of traditional and molecular techniques. Mycology. 3 (1): $65-76$ 